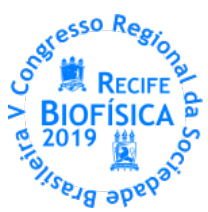

\title{
ESTUDO DA INTERAÇÃO DE LÍQUIDOS IÔNICOS ANFIFÍLICOS COM SISTEMAS BIOMIMÉTICOS DE MEMBRANA: UMA ABORDAGEM ESTRUTURAL E ESPECTROSCÓPICA
}

\author{
Natália F. de Oliveira ${ }^{1}$, Leandro R. S. Barbosa ${ }^{1}$ \\ ${ }^{1}$ Instituto de Física, Universidade de São Paulo,São Paulo,SP
}

\section{RESUMO}

Os Líquidos lônicos (LIs) são uma classe interessante de moléculas orgânicas que tem sido objeto de diferentes estudos nos últimos anos. Tipicamente, eles são compostos por um cátion orgânico e um ânion orgânico ou inorgânico, e podem ser encontrados no estado líquido a temperaturas abaixo de $100^{\circ} \mathrm{C}$. Devido a sua geometria peculiar, estes compostos possuem uma vasta gama de aplicações em diversas áreas do conhecimento como química verde, farmacologia, biomedicina e bionanotecnologia. Apesar disso, pesquisas recentes mostraram que a toxicidade dos Lls é maior do que se acreditava anteriormente, particularmente com sistemas de relevância biológica. 0 principal objetivo deste projeto é obter mais informações sobre a interação do líquido iônico cloreto de 1-tetradecil-3-metilimidazólio ([C14mim]Cl) em sistemas de membranas biomiméticas para identificar os mecanismos moleculares por trás de sua toxicidade. Para isso, utilizamos diferentes lípidios para a composição de vesículas, a fim de simular o comportamento da membrana plasmática celular de eritrócitos e analisar a influência de diferentes concentrações de Lls em suas propriedades estruturais. As interações entre estes sistemas lipídicos e a LI em questão foram estudadas através da microscopia eletrônica de transmissão, espalhamento dinâmico de luz e vazamento de sonda fluorescente. De acordo com os resultados, o LI incorporou na bicamada: o diâmetro hidrodinâmico das vesículas aumentou de $(145 \pm 1) \mathrm{nm}$ para $(160 \pm 1) \mathrm{nm}$ conforme o LI foi adicionado, e nas micrografias foi possível ver uma região escura em torno das vesículas, que não existia nos sistemas sem o líquido iônico. Em relação ao vazamento, nenhum efeito foi evidenciado, pelo menos para razões LI:Lipídio menores que 3:10, confirmando mais uma vez que o LI possivelmente está se inserido na parte externa da vesícula. Agradecimentos: FAPESP (\#2018/04796-8), CNPq, SBBf. 